\title{
Developing a Mindfulness Skills-Based Training Program for Resident Physicians
}

Vincent Minichiello, MD; Supriya Hayer, MD; Bob Gillespie, MD; Maureen Goss, MPH; Bruce Barrett, MD, PhD

BACKGROUND AND OBJECTIVES: Resident physicians experience a high level of stress. Mindfulness meditation has been shown to offer medical students and physicians a healthier way to relate to daily stressors. We developed and pilot tested a mindfulness training program and assessed its impact on resident physician burnout and resilience.

METHODS: The residency program offered 17 family medicine residents a 10-hour mindfulness training over the course of 2 months in 2016. Residents were encouraged, but not mandated, to attend. Experienced MindfulnessBased Stress Reduction teachers and a family physician/integrative health fellow cotaught the program. A research team qualitatively assessed deidentified, postintervention resident interviews. Residents completed four quantitative questionnaires preintervention, immediately postintervention, and 3 months postintervention. A t score was calculated to assess for statistical significance.

RESULTS: Three residents (18\%) attended all five training sessions, seven residents (41\%) completed at least four sessions, and 16 residents (94\%) completed either one or two sessions. Eight residents completed the postintervention interview. Twelve, nine and 14 residents completed the four questionnaires at the three time points, respectively. Qualitative results identified multiple personal/professional benefits of participating in mindfulness training, and we found a statistically significant decrease in perceived stress and increase in mindful awareness from pre- to postintervention $(P<.05)$.

CONCLUSIONS: A resident physician mindfulness training program can be reasonably integrated into the residency schedule as part of the wellness curriculum required by the Accrediation Council for Graduate Medical Education. Preliminary results show potential for personal growth and positive changes in patient relationships.

(Fam Med. 2020;52(1):48-52.)

doi: $10.22454 /$ FamMed.2020.461348

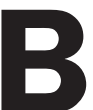

urnout is characterized by overwhelming exhaustion, feelings of detachment from one's job, and a sense of ineffectiveness and lack of accomplishment. Symptoms of burnout are reported by family physicians at a rate found that 41 out of 42 resident respondents experienced some degree of burnout during training, based on an informal needs assessment.

Mindfulness has been defined as "paying attention in a particular way: on purpose, in the present moment, and nonjudgmentally," ${ }^{4}$ and may allow physicians to cultivate a healthier relationship with stress. ${ }^{5-7}$ Improvement in self-compassion, empathy, ${ }^{8,9}$ burnout, ${ }^{1}$ and positive affect, ${ }^{10}$ as well as decreased overreactions to stress ${ }^{2}$ have been reported in mindfulness programs for resident physicians. Research indicates that brief programs may be beneficial. ${ }^{11,12}$ As part of our efforts to support resident well-being and professional development, we assessed the impact of a 10-hour training program on residents' burnout experiences.

\section{Methods \\ Program Development and Participants}

We designed a five-session, 10-hour curriculum (Table 1). Participation was strongly encouraged for 17 firstyear family medicine residents. The training occurred during scheduled didactic time on a weekly or biweekly basis in fall 2016 . The University

significantly higher than other medical specialties (63\%) and can result in increased rates of medical errors and lower patient adherence. ${ }^{1,2} \mathrm{~A}$ high level of stress-related burnout during residency training is also well documented. ${ }^{3}$ In our program, we
From the Department of Family Medicine and Community Health, School of Medicine and Public Health, University of Wisconsin, Madison, WI (Drs Minichiello, Hayer, and Barrett, and Ms Goss); and University of Wisconsin Health, Madison, WI (Dr Gillespie). 
Table 1: 10-Hour Adapted Mindfulness-Based Stress Reduction Curriculum

\begin{tabular}{|c|c|c|}
\hline $\begin{array}{l}\text { Session } \\
\text { Number }\end{array}$ & Class Theme & Content* \\
\hline $\begin{array}{l}\text { Class } 1 \\
(1.5 \text { hours })\end{array}$ & $\begin{array}{l}\text { Being vs } \\
\text { doing (moving } \\
\text { between mind } \\
\text { frames of } \\
\text { doing tasks } \\
\text { and simply } \\
\text { being in the } \\
\text { present) }\end{array}$ & $\begin{array}{l}\text { - Large group discussion about movement practice } \\
\text { - Introduction to the mindfulness program } \\
\text { - Six-point body acan (bringing attention to six body regions) } \\
\text { - Small, then large group discussion of body scan: (1) What did you notice? What arose } \\
\text { in your experience? (2) How does this way of paying attention differ from how we } \\
\text { usually pay attention? (3) What could this have to do with stress reduction? } \\
\text { - Homework: formal: daily practice of six-point body scan or mindful movement; } \\
\text { informal: pick one to two transitions to bring attention to over the course of the } \\
\text { week }\end{array}$ \\
\hline $\begin{array}{l}\text { Class } 2 \\
(1.5 \text { hours })\end{array}$ & $\begin{array}{l}\text { Transition } \\
\text { practices, } \\
\text { working with } \\
\text { limited time } \\
\text { (bringing } \\
\text { awareness to } \\
\text { in between } \\
\text { moments of } \\
\text { daily life) }\end{array}$ & $\begin{array}{l}\text { - Repeat six-point body scan } \\
\text { - Large group check-in about practice } \\
\text { - Discussion of transition practices (VM shared clinical story, discussed times during the } \\
\text { day to practice transitions-logging into the EMR, change of shift) } \\
\text { - Introduce mindful listening/speaking (Working in dyads around transitions. Asking: in } \\
\text { what ways do I notice that my time is limited throughout a day of clinical care?) } \\
\text { - Three breaths practice (see above) practiced at transitions throughout class } 2 \\
\text { - } \text { Homework: formal: body scan or movement practice once daily; informal: paying } \\
\text { put in places they commonly go to throughout their day as reminders to breathe }\end{array}$ \\
\hline $\begin{array}{l}\text { Class } 3 \\
(1.5 \text { hours })\end{array}$ & $\begin{array}{l}\text { Compassion } \\
\text { practices } \\
\text { (cultivating } \\
\text { compassion } \\
\text { in a way that } \\
\text { is sustainable } \\
\text { in clinical and } \\
\text { personal lives) }\end{array}$ & $\begin{array}{l}\text { - Tracing fingers breathing exercise (trace finger to tip on inhale, trace finger to base on } \\
\text { exhale, complete } 20 \text { breaths by tracing all fingers in one direction and back) } \\
\text { - Large group check in about today's practices and home practice for this past week } \\
\text { - Read excerpt from Medicine and Compassion book by Rinpoche and Shlim } \\
\text { - Caring moments meditation-practicing receiving compassion; adapted from "Sustainable } \\
\text { Compassion Training" (http://foundationforactivecompassion.com/audios-videos-texts) } \\
\text { - Dyad mindful listening/speaking (Question: in what ways can you develop a form of } \\
\text { compassion that is long-lasting? What challenges come up in this process?) } \\
\text { - Homework: formal: caring moments practice, body scan, movement practices; informal: } \\
\text { walking meditation during one daily walk; noticing one moment of compassion and } \\
\text { reflecting }\end{array}$ \\
\hline $\begin{array}{l}\text { Class } 4 \\
(1.5 \text { hours })\end{array}$ & $\begin{array}{l}\text { Compassion } \\
\text { practices, } \\
\text { feeling } \\
\text { powerless } \\
\text { (discussing } \\
\text { compassion in } \\
\text { the context of } \\
\text { the resident } \\
\text { experience) }\end{array}$ & $\begin{array}{l}\text { - Walking meditation } \\
\text { - Revisiting caring moments practice } \\
\text { - Large group check-in-how has practice been going at home? What challenges arose? In } \\
\text { what ways can you develop a form of compassion that is long-lasting? } \\
\text { - Read Imperfections poem by Elizabeth Carlson (Vinny) } \\
\text { - Homework: formal: alternate between body scan, movement practice, or a caring } \\
\text { moments practice; consider repeating loving-kindness meditation phrases daily; } \\
\text { informal: continue simply noticing-transitions throughout the day, steps taken while } \\
\text { walking from place to place; consider ways I may learn to love my imperfections }\end{array}$ \\
\hline $\begin{array}{l}\text { Class } 5^{* *} \\
(4 \text { hours) }\end{array}$ & $\begin{array}{l}\text { Compassionate } \\
\text { self-care } \\
\text { (taking time } \\
\text { to develop } \\
\text { a sense of } \\
\text { feeling at } \\
\text { home in } \\
\text { one's own life } \\
\text { experience) }\end{array}$ & $\begin{array}{l}\text { - Lying down-body scan (resident self-directed) } \\
\text { - Check in about the body scan practice-What did you notice (one thing)? } \\
\text { - } \text { Setting tone for the day-compassionate care; practicing silence; reading a poem } \\
\text { - } 5 \text { mindful eating; if finish early-lie back down and rest until everyone is done } \\
\text { difference } \\
\text { - Breath awareness practice } \\
\text { - } \text { Equanimity practice } \\
\text { - Coming out of silence/dyads inquiry practice (Question: what did you notice today?) } \\
\text { course that might support your compassionate self-care? What's your intention } \\
\text { - Ground compassionate self-care moving forward? }\end{array}$ \\
\hline
\end{tabular}

* Each class included mindful movement—-bringing awareness and attention to body sensations, thoughts, and emotions that arose when practicing variations of yoga postures, Qigong (slow, intentional movements coordinated with breath and/or focused attention), and gentle stretching.

** We chose to prolong the final class from 1.5 to 4 hours to mirror the all-day experience that is central to Mindfulness-Based Stress Reduction (MBSR) training, to review previously facilitated mindfulness practices, and to allow time for group processing of the entire mindfulness training program. This final class had the greatest attendance of all the sessions. 
of Washington Health Sciences Minimal Risk Institutional Review Board exempted this educational study.

\section{Qualitative Assessment}

Residents were invited to participate in confidential, posttraining phone interviews (Table 2) with optional recording conducted by a physician-researcher (author S.H.) not associated with the training. Responses were transcribed.

Transcripts were read by six reviewers: four integrative health fellows (including V.M.), a family physician with a doctorate degree in anthropology (B.B.), and a senior mindfulness instructor. Prior to reviewing transcripts, all readers went through a bracketing process in which they answered a series of reflective questions on their sociocultural background and relationship with the subject matter. Reflection fosters awareness of readers' strengths and/or limitations that result from their backgrounds, thus improving the quality of the reviewing process. Readers reviewed transcripts twice, following a modified interpretative phenomenological analysis approach..$^{13}$ Readers met to discuss notations and emergent themes during six in-person meetings.

The lead investigator (V.M.) condensed the themes (Table 3), shared results with all readers, and conducted one member-checking session with six residents. There were no disagreements among readers or residents with the condensed themes.

\section{Quantitative Assessment}

Residents completed surveys prior to the mindfulness training, immediately afterwards, and 3 months posttraining. Surveys included the Maslach Burnout Inventory, ${ }^{14}$ Perceived Stress Scale-10, ${ }^{15}$ Brief Resilience Scale (assessing one's ability to bounce back from stress), ${ }^{16}$ and Five Facet Mindfulness Questionnaire (measuring an individuals' experience of mindfulness). ${ }^{17}$ These measures feature prominently in burnout and mindfulness literature, have a short completion time (15 minutes), and encompass outcomes of interest. Qualtrics online survey software (Provo, UT: Qualtrics; 2018) was utilized to collect and organize the data.

Data were compared on each measure from baseline to 2- and 5-month values and between 2 - and 5-month values, and tested for significance using unpaired, two-sample $t$ tests. Self-report bias was minimized by ensuring anonymity.

\section{Results}

Of the 17 first-year family medicine residents, 10 participated in at least four of the five sessions, and 16 completed one or two sessions.

\section{Qualitative Assessment}

Eight residents completed postintervention interviews, and saturation was reached after reviewing these interviews. Reviewers identified three themes during qualitative analysis: (1) experiences of burnout and its causes, (2) change/growth in personal life and relationship to stressors, and (3) changes in patient relationships (Table 3).

Residents provided positive programming feedback including: (1) appreciating the community space provided to practice mindfulness, (2) participating in a training rather than check-in discussion groups, (3) holding sessions during the first year of residency, and (4) one of the teachers (V.M.) was a family physician. One point of contention amongst respondents was about whether the program should be mandatory or voluntary.

\section{Quantitative Assessment}

Eight residents completed all measures at all three time points (Table 4). Average scores showed significant improvement in depersonalization, perceived stress, and experience of mindfulness. All respondents moved out of the "high levels of burnout" range in the emotional exhaustion and depersonalization subscales.

\section{Discussion}

We implemented a mindfulness program during residency training. Most residents (59\%) voluntarily attended at least four of the five sessions. Both qualitative and quantitative assessments suggest that this program may improve burnout, resilience, perceived stress, and level

Table 2: Interview Questions

1. How is residency going?

2. How was your experience of the mindfulness training?

3. How has this training affected your experience of residency? [Prompts: Many residents express a sense of burnout during their residency training. What are common factors that cause burnout in you or other residents you know? How do you perceive that mindfulness may have an effect on those burnout factors?]

4. How has this training influenced your clinical practice? [prompts: what has changed in how you approach patient care? what has changed in how you interact with patients?]

5. How many days per week and minutes per day did you use these mindfulness practices? How much of the time was spent with informal practices (for example, brief awareness practices throughout the day)? How much time was spent with formal practices (for example, sitting meditations, body scans)?

6. Would you recommend continuing this mindfulness training within your own residency program? Would you recommend other residency programs adopt a similar mindfulness training curriculum? [Prompts: Do you think this program would be helpful for other residents-either residents within your program or in other programs?]

7. What would you change about the content and/or delivery of this curriculum? (Prompts: If this program were to be run again, how would you improve it?] 
Table 3: Themes and Responses From Qualitative Analysis of Eight Resident Interviews

\begin{tabular}{|c|c|}
\hline Theme & Responses \\
\hline Experience of burnout and its causes & $\begin{array}{l}\text { - Overwhelmed by emotional needs of patients } \\
\text { - Patient expectations } \\
\text { - Documentation } \\
\text { - Long days (two respondents) } \\
\text { - "Not having time to do real life stuff" }\end{array}$ \\
\hline $\begin{array}{l}\text { Change/growth in personal life and relationship to } \\
\text { stressors }\end{array}$ & $\begin{array}{l}\text { - "Reset" (three respondents) } \\
\text { - "Mindful of overwhelming feelings...keeping a larger view" } \\
\text { - "Stepping back" } \\
\text { - "Letting go" } \\
\text { - "Take a moment" } \\
\text { - Increased awareness of mind racing and interruption of that } \\
\text { process }\end{array}$ \\
\hline Change in patient relationships & $\begin{array}{l}\text { - Meaningful care } \\
\text { - Discuss mindfulness with patients (three respondents), } \\
\text { - Feeling better prepared when walking into a difficult patient } \\
\text { encounter } \\
\text { - Being present with patients } \\
\text { - } \text { "Meet them where they're at" }\end{array}$ \\
\hline
\end{tabular}

Three themes and the responses that led to identification of each theme. Themes were supported by at least two resident respondents.

Table 4: Means and Standard Deviations of Self-Report Instrument

\begin{tabular}{|l|c|c|c|}
\hline \multicolumn{1}{|c|}{ Instrument } & $\begin{array}{c}\text { Baseline, } \mathbf{n = 1 2} \\
\text { Mean (95\% } \mathbf{~ C l )}\end{array}$ & $\begin{array}{c}\text { 2-Month Follow-up, } \mathbf{n = 9} \\
\text { Mean (95\% Cl) }\end{array}$ & $\begin{array}{c}\text { 5-Month Follow-up, } \mathbf{n = 1 4} \\
\text { Mean (95\% Cl) }\end{array}$ \\
\hline MBI Section A* & $18.0(14.8,21.2)$ & $16.7(12.1,21.3)$ & $16.4(13.7,19.2)$ \\
\hline MBI Section B* & $15.5(13.1,17.9)$ & $12.2(8.9,15.5)$ & $11.6^{* *}(9.6,13.7)$ \\
\hline MBI Section C* & $39.9(37.6,42.2)$ & $42.0(40.2,43.8)$ & $41.9(40.3,43.6)$ \\
\hline PSS-10 & $15.8(14.0,17.6)$ & $13.0^{* *}(11.9,14.2)$ & $14.1(12.2,16.0)$ \\
\hline BRS & $3.7(3.4,3.9)$ & $3.8(3.4,4.1)$ & $3.9(3.7,4.1)$ \\
\hline FFMQ & $129.0(128.4,129.6)$ & $143.1^{* *}(137.1,149.1)$ & $141.1^{* *}(131.3,150.9)$ \\
\hline
\end{tabular}

Abbreviations: CI, confidence interval; MBI, Maslach Burnout Inventory; PSS, Perceived Stress Scale; BRS, Brief Resilience Scale; FFMQ, Five Facet Mindfulness Questionnaire

* Section A: Emotional Exhaustion (max score 42, <17 low level burnout) Section B: Depersonalization (max score 42, >12 high-level burnout); Section C: Personal Achievement (max score 48, <33 high level burnout); PSS-10: max score 40; BRS: max score 30; FFMQ (includes observing, describing, acting with awareness, nonjudging inner experience, nonreactivity to inner experience), max score 195.

** Significant difference from baseline

of mindful awareness, while having positive influences on residents' personal lives and clinical practice. Positive responses about the training format and content provide support for the program, and the likelihood of implementing and evaluating similar programs.

Our program is the first to quantitatively and qualitatively assess a brief mindfulness curriculum for resident physicians that is integrated into residency training. Quantitative results suggest that participating residents noticed lower amounts of depersonalization and perceived stress in their work, while incorporating a greater understanding of mindfulness meditation into their lives. These data are corroborated in the residents' interviews as they acknowledge a shift in their relationships to stressors-a shift that carried over into their personal and professional lives.

Study strengths included collaboration of readers from diverse backgrounds, the use of a bracketing process, incorporating resident feedback, and group facilitation by experienced mindfulness teachers. Finally, as a training embedded within a standard didactic curriculum, our program avoided adding responsibilities to the already full lives of resident physicians, supporting healthy physician learning and practice. ${ }^{18-20}$

This study had several limitations. This was a small-scale observational study with no control group. Rotation scheduling constraints prevented some residents from attending classes. Attendance was not tracked to support resident privacy, so we could not assess any association between attendance and the quantitative measures over time, nor can we 
conclude that regular attendance is associated with congruent benefits described in the qualitative assessment.

This study describes a mindfulness program for resident physicians. Our findings suggest this program can be reasonably integrated into the residency curriculum, and that mindfulness may be an effective way for residents to enhance resilience, and prevent and navigate burnout.

ACKNOWLEDGEMENTS: The authors express gratitude for the collaborative efforts and support of the UW Department of Family Medicine and Community Health, the UW Integrative Health program, and the UW Health Mindfulness Program. The authors thank Shari Barlow for her work in project management, in addition to continued support of the process involved in coordinating this resident mindfulness curriculum. They also thank Mindy Smith, MD, for her contributions through editing and advising on this manuscript.

FINANCIAL SUPPORT: The University of Wisconsin-Madison Department of Family Medicine and Community Health (UW-DFMCH) Small Grants Program contributed funding for this projec,t in addition to the UW Integrative Health program's George Washington Institute for Spirituality and Health grant. During this project, Bruce Barrett was supported by a midcareer research and mentoring grant from the National Center for Complementary and Integrative Health (K24AT006543).

PRESENTATIONS: Minichiello V. Being with burnout: the development and evaluation of a 10-hour mindfulness training for resident physicians. University of Cincinnati, Hematology/Oncology Grand Rounds Presentation. Cincinnati, OH. May 18, 2018.

Minichiello V. Developing an adapted mindfulness based stress reduction program for resident physicians. Guest speaker at Madison, Wisconsin VA Hospital's monthly Integrative Health and Wellness Committee meeting. June $14,2017$.

Minichiello V. Being with burnout. University of Wisconsin, Anesthesiology Grand Rounds Presentation. Madison, WI. October 10, 2018.
Minichiello V. Introduction to STREaM: Supportive Training for Residents through Education in Mindfulness. University of Wisconsin, Madison, Graduate Medical Education Committee Meeting. Madison, WI. October 17, 2018

CORRESPONDING AUTHOR: Address correspondence to Dr Vincent J. Minichi ello, Department of Family Medicine and Community Health, School of Medicine and Public Health, University of Wisconsin, 1100 Delaplaine Ct, Madison, WI 53715. 978-979-0621. Fax: 608-251-2332.

Vincent.Minichiello@fammed.wisc.edu.

\section{References}

1. Goldhagen BE, Kingsolver K, Stinnett SS, Rosdahl JA. Stress and burnout in residents: impact of mindfulness-based resilience training. Adv Med Educ Pract. 2015;6:525-532.

2. Brennan J, McGrady A. Designing and implementing a resiliency program for family medicine residents. Int J Psychiatry Med. 2015;50(1):104-114

3. Dyrbye LN, West CP, Satele D, et al. Burnout among U.S. medical students, residents, and early career physicians relative to the general U.S. population. Acad Med. 2014;89(3):443-451.

4. Kabat-Zinn J. Wherever You Go, There You Are: Mindfulness Meditation in Everyday Life. 10th ed. New York: Hachette Books; 2005.

5. Krasner MS, Epstein RM, Beckman H, et al. Association of an educational program in mindful communication with burnout, empathy, and attitudes among primary care physicians. JAMA. 2009;302(12):1284-1293.

6. Fortney L, Luchterhand C, Zakletskaia L, Zgierska A, Rakel D. Abbreviated mindfulness intervention for job satisfaction, quality of life, and compassion in primary care clinicians: a pilot study. Ann Fam Med. 2013;11(5):412-420.

7. Goodman MJ, Schorling JB. A mindfulness course decreases burnout and improves wellbeing among healthcare providers. Int J Psychiatry Med. 2012;43(2):119-128.

8. Runyan C, Savageau JA, Potts S, Weinreb L. Impact of a family medicine resident wellness curriculum: a feasibility study. Med Educ Online. 2016;21(1):30648.

9. Verweij H, van Ravesteijn H, van Hooff MLM, Lagro-Janssen ALM, Speckens AEM. Mindfulness-Based Stress Reduction for Residents: A Randomized Controlled Trial. J Gen Intern Med. 2018;33(4):429-436.
10. Wen L, Sweeney TE, Welton L, Trockel M, Katznelson L. Encouraging Mindfulness in Medical House Staff via Smartphone App: A Pilot Study. Acad Psychiatry. 2017;41(5):646650

11. Carmody J, Baer RA. How long does a mindfulness-based stress reduction program need to be? A review of class contact hours and effect sizes for psychological distress. J Clin Psychol. 2009;65(6):627-638.

12. Romcevich LE, Reed S, Flowers SR, Kemper KJ, Mahan JD. Mind-Body Skills Training for Resident Wellness: A Pilot Study of a Brief Mindfulness Intervention. J Med Educ Curric Dev. 2018;5:2382120518773061.

13. Smith JA, Flowers P, Larkin M. Interpretative phenomenological analysis : theory, method and research. [Internet] London: SAGE Publications Ltd; 2009, Available from https://trove. nla.gov.au/version/164877353. Accessed November $1,2018$.

14. Maslach C, Jackson SE, Leiter MP. Maslach Burnout Inventory Manual [Internet]. 3rd ed. Palo Alto, CA: Consulting Psychologists Press; 1996 [cited 2018 Nov 1]. https://trove.nla.gov. au/version/18762965. Accessed July 18, 2019.

15. Cohen S. Perceived Stress Scale-Mind Garden [Internet]. Menlo Park, CA: Mind Garden, Inc; 1994. http://www.mindgarden.com/documents/ PerceivedStressScale.pdf. Accessed November 1,2018

16. Smith BW, Dalen J, Wiggins K, Tooley E, Christopher P, Bernard J. The brief resilience scale: assessing the ability to bounce back. Int J Behav Med. 2008;15(3):194-200.

17. Baer RA, Smith GT, Hopkins J, Krietemeyer J, Toney L. Using self-report assessment methods to explore facets of mindfulness. Assessment. 2006;13(1):27-45.

18. Konopasek L, Slavin S. Addressing Resident and Fellow Mental Health and Well-Being: What Can You Do in Your Department? J Pediatr. 2015;167(6):1183-4.e1.

19. Ludmerer KM, Johns MME. Reforming graduate medical education. JAMA. 2005;294(9):1083-1087.

20. Verweij H, van Ravesteijn H, van Hooff MLM, Lagro-Janssen ALM, Speckens AEM. Does Mindfulness Training Enhance the Professional Development of Residents? A Qualitative Study. Acad Med. 2018;93(9):1335-1340. 